Dermatology 2014;228:132-133

DOI: $10.1159 / 000357403$

\section{Epicardial Fat Thickness in Psoriasis Patients}

Ilknur Balta a , Sevket Balta ${ }^{\mathrm{b}}$, Cengiz Ozturk' ${ }^{\mathrm{b}}$, Sait Demirkol', Mustafa Demir

a Department of Dermatology, Keçioren Training and Research Hospital, Ankara, ${ }^{\mathrm{b}}$ Department of Cardiology, Eskişehir Military Hospital, Eskişehir, and ' Department of Cardiology, Gulhane Medical Academy, Ankara, Turkey

Dear Editor,

We have read the article 'Epicardial Fat Thickness Is Independently Associated with Psoriasis' written by Akyildiz et al. with a great interest [1]. The authors aimed to compare the epicardial fat thickness (EFT) in psoriasis patients with that in control subjects. They concluded that EFT, which has been suggested as a cardiometabolic risk factor in various diseases, is also independently associated with psoriasis. Thanks to the authors for their contribution of the present study, which is successfully designed and documented.

Epicardial adipose tissue functions as an active endocrine organ that produces several cytokines involved in oxidative stress, atherosclerosis, inflammation and angiogenesis [2]. Various studies have highlighted the potential importance of adipose tissue in relation to inflammatory burden in cardiovascular diseases. EFT is a new parameter that has recently attracted attention as a measure of predisposition to atherosclerosis. Studies have reported that EFT thickness measured using echocardiography is associated with atherosclerosis in patients with coronary artery disease, hypertension, type 2 diabetes, metabolic syndrome, hypothyroidism and chronic kidney disease [3]. Primary hyperparathyroidism affects the cardiovascular system, and EFT is closely associated with cardiovascular diseases and atherosclerosis. EFT may be a useful marker of early atherosclerosis in patients with primary hyperparathyroidism [4]. EFT may be included among the clinical parameters associated with obstructive sleep apnea severity. The association of EFT with obstructive sleep apnea, both cardiovascular risk factors, is independent of obesity as defined by classical measures [5]. EFT amount may contribute to systemic inflammation beyond traditional cardiovascular risks and body fat composition. EFT measured by echocardiography has been known to be associated with metabolic syndrome [6]. Additionally, echocardiography-based EFT measurement was related to several metabolic abnormalities and independently associated with fatty liver disease [7].

Echocardiographic EFT measurement in both clinical and research scenarios has several advantages, including its low cost, easy accessibility, rapid applicability and good reproducibility. However, more evidence is necessary to evaluate whether echocardio- graphic EFT may become a routine way of assessing cardiovascular risk in a clinical setting [8]. Psoriasis is associated with an increased risk of cardiovascular disease. Endothelial dysfunction is widely regarded as being the initial lesion in the development of atherosclerosis [9]. In a previous study, the authors demonstrated that EFT is increased in patients with psoriasis, and that echocardiographic EFT is closely correlated with surrogate inflammatory markers such as carotid intima media thickness in patients with psoriasis [10]. The echocardiographic assessment of EFT may have the potential to be a simple marker of subclinical atherosclerosis and increased cardiovascular risk in patients with psoriasis [10].

The gold standard in assessing EFT is magnetic resonance imaging (MRI); the lack of MRI use is one of the limitations of the present study. Although EFT by echocardiography has natural errors in comparison with computed MRI, EFT measurement with echocardiography has several advantages, including its inexpensiveness, easy accessibility, rapid applicability and good reproducibility. However, echocardiography cannot be the optimal technique for quantification of epicardial fat. Since echocardiography measures EFT linearly and EFT has a three-dimensional distribution, two-dimensional echocardiography may not give adequate information about the total epicardial fat volume [11]. Also, EFT was calculated on the free wall of the right ventricle in the still images obtained at end diastole on both parasternal long-axis and short-axis views. The anterior echolucent space between the right ventricle outer wall and the linear echodense parietal pericardium was considered to be epicardial fat. When EFT is measured, mediastinal fat, presenting as an echolucent area above the parietal pericardium, should be excluded. Also, the mean value of two images obtained in the parasternal long-axis and short-axis views should be calculated. Additionally, it would be better to give inter- and intraobserver variability for epicardial adipose tissue measurement in the current study [12].

As a conclusion, EFT itself without other inflammatory markers may not provide information to clinicians about systemic inflammation [13]. Thus, we think that it should be evaluated together with other serum inflammatory markers. We believe that these findings will evaluate further studies about EFT in psoriasis patients.

\section{References}

1 Akyildiz ZI, Seremet S, Emren V, Ozcelik S, Gediz B, Tastan A, Nazlı C: Epicardial fat thickness is independently associated with psoriasis. Dermatology DOI: 10.1159/000354726.

2 Katsiki N, Mikhailidis DP, Wierzbicki AS: Epicardial fat and vascular risk: a narrative review. Curr Opin Cardiol 2013;28:458-463.

-3 Balta S, Demırkol S, Kucuk U, Arslan Z, Unlu M, Yesil FG: Epicardial adipose tissue should be evaluated with other inflammatory markers in patients with subclinical hypothyroidism. Med Princ Pract 2013;22:603.

-4 Asik M, Sahin S, Temiz A, Ozkaya M, Ozkul F, Sen H, Binnetoglu E, Gunes F, Bozkurt N, Sahin M, Ukinc K: Evaluation of epicardial fat tissue thickness in patients with primary hyperparathyroidism. Endocr Pract 2014;20:26-32.

\section{KARGER}

E-Mail karger@karger.com

www.karger.com/drm
() 2014 S. Karger AG, Base

$1018-8665 / 14 / 2282-0132 \$ 39.50 / 0$
Dr. Sevket Balta

Department of Cardiology

Eskisehir Military Hospital

Eskișehir (Turkey)

E-Mail drsevketb@gmail.com 
5 Mariani S, Fiore D, Barbaro G, Basciani S, Saponara M, D’Arcangelo E, Ulisse S, Moretti C, Fabbri A, Gnessi L: Association of epicardial fat thickness with the severity of obstructive sleep apnea in obese patients. Int J Cardiol 2013;167:2244-2249.

6 Balta S, Demirkol S, Arslan Z, Unlu M, Kucuk U, Iyisoy A: Epicardial fat thickness should be evaluated with other inflammatory markers and cardiovascular risk factors. Echocardiography 2013;30:739.

$>7$ Lai YH, Yun CH, Yang FS, Liu CC, Wu YJ, Kuo JY, Yeh HI, Lin TY, Bezerra HG, Shih SC, Tsai CH, Hung CL: Epicardial adipose tissue relating to anthropometrics, metabolic derangements and fatty liver disease independently contributes to serum high-sensitivity C-reactive protein beyond body fat composition: a study validated with computed tomography. J Am Soc Echocardiogr 2012;25:234-241.

8 Iacobellis G, Willens HJ: Echocardiographic epicardial fat: a review of research and clinical applications. J Am Soc Echocardiogr 2009;22:13111319, quiz 1417-1418.
9 Balta I, Balta S, Demirkol S, Mikhailidis DP, Celik T, Akhan M, Kurt O, Kurt YG, Aydin I, Kilic S: Elevated serum levels of Endocan in patients with psoriasis vulgaris: correlations with cardiovascular risk and activity of disease. Br J Dermatol 2013;169:1066-1070.

10 Bulbul Sen B, Atci N, Rifaioglu EN, Ekiz O, Kartal I, Buyukkaya E, Kurt M, Karakas MF, Buyukkaya S, Akcay AB, Sen N: Increased epicardial fat tissue is a marker of subclinical atherosclerosis in patients with psoriasis. Br J Dermatol 2013;169:1081-1086.

11 Balta S, Demirkol S, Kurt Ö, Sarlak H, Akhan M: Epicardial adipose tissue measurement: inexpensive, easy accessible and rapid practical method. Anadolu Kardiyol Derg 2013;13:611.

12 Şengül C, Özveren O: Epicardial adipose tissue: a review of physiology, pathophysiology, and clinical applications. Anadolu Kardiyol Derg 2013; 13:261-265.

13 Balta S, Demirkol S, Kucuk U, Unlu M, Dinc M, Arslan Z: Epicardial fat thickness and cardio-ankle vascular index without other inflammatory markers may not provide information to clinicians about the systemic inflammation. Cardiology 2013;125:13-14. 